\title{
Comparison Study to Evaluate the Color Changes of Two Different Types of Resin-Based Composites
}

\author{
Firas Ibrahim Hani, B.D.S, M.Sc.
}

\begin{abstract}
Anin vitro study to compare the color changes of two different types of resin-based composite after staining, the study was done on prepared composites rings with $12 \mathrm{~mm}$. in diameters and $2 \mathrm{~mm}$. in thickness and the colorrecords were taken with Vita Easyshade spectrophotometer.
\end{abstract}

Keywords: Resin composites, color stability, tea solutions and easy shade

\section{Aim}

The aim of this study was to evaluate the color changes of two different types of dental composites after staining with daily consumed drinks.

\section{Clinical Significance}

In spite of many improvements in chemical compositions and fillers of the contemporary resin composites, the color changes after aging were still perceptible in all the resin composites, regardless of their types and brands. Such changes may cause esthetic problems clinically, thus should be taken into account when the shade selections are performed.

\section{Introduction}

The color stability of stained resin based-based composites as with any other esthetic restorative dental material is considered to be an important factor in the success of composites and patient satisfaction ${ }^{(1)}$. However, for resin composites, restorative materials discoloration after prolonged exposure to the oral environment is still a major clinical problem and a main cause of restoration replacement (2) (3)

The amount of discoloration is multifactorial and includes factors that are intrinsic to resin, such as the resin matrix fillers, interface of matrix and fillers, water sorption, shades, photo initiators and degree of conversion of carbon-carbon double bonds ${ }^{(4)}$. Extrinsic factors such as absorption and adsorption of colorants from food, beverages, colored mouth rinses, ultraviolet radiation, thermo cycling, smoking habits, oral hygiene and polishing and finishing procedures may also influencing extrinsic staining ${ }^{(5)(6)}$.

Much of the initial esthetic success of restorations depends on good color match between the tooth and the restorative material. The increased concern on esthetic appearance in today's society had led to consider the color stability of esthetic restorations as critical factor for long term success of such restorations ${ }^{(7)(8)}$. The color stability is an important factor for the direct and indirect esthetic restorations and is fundamental to the success of the restorative treatment ${ }^{(8)}$.

Many studies investigated the color stability of dental composites upon immersion in coffee, tea and beverages (9)(10)(11). The authors concluded that polished surfaces, low water sorption, a high filler-resin ratio, reduced particle size and hardness and optimal filler-matrix coupling system helped to improve the composite resistance to discoloration $^{(12)(13)}$

\section{Materials and methods}

Twenty composite rings were made with $12 \mathrm{~mm}$. in diameter and $2 \mathrm{~mm}$. in thickness ${ }^{(14)}$.Five rings were made in group A,five rings were made for group B. Group A composite rings were made with Heliomolar universal (microfiller) composite for anterior and posterior fillings from ivoclarvivadent corporate. Group B composite rings were made with Spectrum ${ }^{\circledR} \mathrm{TPH}^{\circledR} 3$ - a visible light-activated, radiopaque sub-micron hybrid composite for anterior and posterior restorations. Group C and D each of them composed five composite rings and each of these five rings made from different composite material. The staining procedure was done by immersion of the each group composite rings (group $\mathrm{A} \& \mathrm{~B}$ ) in vials containing tea by keeping the specimens in an incubator at 55 cfor 7-days test periods ${ }^{(15)}$. The tea solutions were made by immersion of two prefabricated tea packs (Ahmed tea, packed in UAE) in boiling water $(500 \mathrm{ml}$.) for 10 minutes and the staining solution (tea) was renewed daily for each specimen ${ }^{(6)(7)}$. For Group C\&D were immersed in distilled water at 37c. After 7-days test period the specimens were rinsed and dried and the records were taken with Vita Easy shadespectrophotometer ${ }^{(16)(17)}$

Table 1: Composites used in this study

\begin{tabular}{|c|c|c|c|}
\hline composite & composition & shade & company \\
\hline $\begin{array}{c}\text { Heliomolar } \\
\text { universal }\end{array}$ & Bis-GMA, Urethane dimethacrylate,Decandioldimethacrylate & Universal & $\begin{array}{c}\text { IvoclarVivadent } \\
\text { Corporate }\end{array}$ \\
\hline Spectrum $^{\circledR}$ TPH $^{\circledR} 3$ & Urethane modified Bis-GMA dimethacrylate,EthoxylatedBisphenol A dimethacrylate & Universal & Dentsply \\
\hline
\end{tabular}




\section{International Journal of Science and Research (IJSR) \\ ISSN (Online): 2319-7064}

Index Copernicus Value (2016): 79.57 | Impact Factor (2015): 6.391

\section{Results and Discussion}

The result of each group were collected and the collected data were analyzed and the results show that the immersion of the 2 types resin-based composites in distilled water produced no perceptible discoloration (less or equal to 1) and the 2 types of resin-based composites produces unacceptable discoloration. The means and standard deviations of color differences of each resin composite are given for solution storage. The statistical analysis (Mean standard deviation)as shown in table 2 revealed the significance effects of the discoloration of the resin-based dental composite brand and storage solution. The group A composite rings which made with Heliomolar universal (microfiller) composite showed more significant discoloration than group B composite rings which made with Spectrum ${ }^{\circledR} \mathrm{TPH}^{\circledR} 3$ - a visible light-activated, radiopaque sub-micron hybrid composite .Both resin-based composite showed clinical unacceptable color changes after immersion in tea. Micro hybrid composite was found to be more color stable. The difference in color changes return to the fact Heliomolar universal (microfiller) dental composite andspectrum ${ }^{\circledR} \mathrm{TPH}^{\circledR} 3$ dental composite each of thesedental composite had its own resin matrix and filler size ${ }^{(18)}$. So the difference in color changes belong to the difference in the resin matrix in addition to filler type and size. As the tea was tested in another studies and showed to cause color changes more than other drinking beverages ${ }^{(19)}$.

Table 2: Mean SD of color changes

\begin{tabular}{|c|c|c|}
\hline Composite & solution & Mean Standard deviation \\
\hline \multirow{2}{*}{ Heliomolar universal } & Tea & 11.25 \\
\cline { 2 - 3 } & Distilled water & 30.21 \\
\hline \multirow{2}{*}{ Spectrum $^{\circledR} \mathrm{TPH}^{\circledR} 3$} & Tea & 8.43 \\
\cline { 2 - 3 } & Distilled water & 22.56 \\
\hline
\end{tabular}

\section{Conclusion}

All efforts should be made to minimize discoloration of composite restorations by adopting excellent polishing techniques. Patients should also be educated on the possibility of the restoration to undergo staining under the influence of beverages

\section{References}

[1] Sabatini C,Campillo , ArefJ.Colorstabilityof ten resinbased restorative materials.JEsthetRestorDent 2012 Jun;24(3):185-199.

[2] Sideridou I, TserkiV, Papanastasiou G.Effect of chemical structure on degree of conversion in lightcured dimethacrylate-based dental resins. Biomaterials. 2002; 23:1819-1829.

[3] Dietschi D, CampnileG,HolzJ,MeyerJM.Comparison of the color stability of ten new generation composites :an in vitro study .Dent Maters 1994 Nov.;10(6):353-362.

[4] Nasim I,NeelakantanP,Sujeer R, SubbaraoCV.Color stability of microfilled, microhybrid and nanocomposite resins-an in vitro study.J Dent 2010;38 Suppl 2:e137e142.

[5] Domingos PA,GarciaPP,OliveiraAL,Palma-Dibb RG. Composite resin color stability: influence of light sources and immersion media.J App Oral Sci 2011 May-Jun;19(3):204-211.

[6] Ren YF,Feng L, Serban D, MalmstromHS.Effects of commomn beverages colorants on color stability of dental composites resins:the utility of thermocycling stain challenge model in vitro.J Dent 2012Jul;40 Suppl 1:e48-e56.

[7] Celik C, Yuzugullu B, Erkut S, Yamanel K. Effects of mouth rinses on color stability of resin composites. Eur J Dent. 2008; 2:247-253.

[8] Lee YK, Lim BS, Kim CW. Influence of illuminating and viewing aperture size on the color of dental resin composites. Dent Mater. 2004; 20:116-123.

[9] Fontes ST, Fernández MR, Moura CM, Meireles SS. Color stability of a nanofill composite: effect of different immersion media. J Appl Oral Sci. 2009; 17:388-91.

[10] Topcu FT, Sahinkesen G, Yamanel K, Erdemir U, Oktay EA, Ersahan S. Influence of different drinks on the colour stability of dental resin composites. Eur J Dent. 2009; 3:50-6.

[11] Tunc ES, Bayrak S, Guler AU, Tuloglu N. The effects of children's drinks on the color stability of various restorative materials. J ClinPediatr Dent. 2009; 34:14750.

[12] Borges A, CaneppeleT, Luz M, et al. Color stability of resin used for caries infiltration after exposure to different staining solutions. Oper Dent. 2014; 39:433440.

[13] Grobler Sr,Hyward R, Wiese S, MoolaMH,Van W KotzeTJ.Spectrophotometric assessment of the effectiveness of opalescence PF 10\%:a 14 month clinical study J Dent 2010Feb;38(2):113-117.

[14] Catelan A, Briso AL, Sundfeld RH, GoiatoMC,dos Santos PH. Color stability of sealed composite resin restorative materials after ultraviolet artificial aging and immersion in staining solutions. Prosthet Dentist 2011; 105:236-241.

[15] Sabatini C.Color stability behavior of methacrylatebased resin composites polymerized with light-emitting diodes and quartz-tungsten-halogen. Oper Dent. 2015; 40:271-281.

[16] Ardu S, BrautV, GutembergD, et al. A long-term laboratory test on staining susceptibility of esthetic composite resin materials. Quintessence Int. 2010; 41:695-702.

[17] Arocha MA, Mayoral JR, LefeverD, et al. Color stability of siloranes versus methacrylate-based composites after immersion in staining solutions. Clin Oral Investig. 2013; 17:1481-1487.

[18] Soares-Geraldo D, ScaramucciT, Steagall-JrW, et al. Interaction between staining and degradation of a composite resin in contact with colored foods. Braz Oral Res. 2011; 25:369-375.

[19] Tan BL, Yap AU, Ma HN, et al. Effect of beverages on color and translucency of new tooth-colored restoratives. Oper Dent. 2015; 40:E56-E65. 